Check for updates

Cite this: Phys. Chem. Chem. Phys., 2019, 21, 1123

Received 16th October 2018 Accepted 11th December 2018 DOI: $10.1039 / \mathrm{c} 8 \mathrm{cp} 06438 \mathrm{e}$

rsc.li/pccp

\title{
Crystallization kinetics of thin water films on Pt(111): effects of oxygen and carbon-monoxide adspecies
}

\author{
Ryutaro Souda (D) and Takashi Aizawa (D) ${ }^{\mathrm{b}}$
}

\begin{abstract}
This paper describes nucleation, epitaxial growth, and wettability of water on Pt(111) and how they are influenced by oxygen and carbon-monoxide adspecies, based on reflection high energy electron diffraction (RHEED), time-of-flight secondary ion mass spectrometry (TOF-SIMS), and temperature-programmed desorption (TPD). Amorphous solid water deposited onto the pristine Pt(111) substrate crystallizes into ice Ih together with a 2D layer at $150 \mathrm{~K}$, whereas ice Ic (stacking disordered ice or a mixture of ice Ic and Ih) is formed preferentially onto oxygenated Pt(111) (CO-adsorbed Pt(111)) at 155-160 K (150 K). The ice nucleation and epitaxial growth tend to be hampered on the oxygenated $\mathrm{Pt}(111)$ surface via hydrogen bond formation with chemisorbed oxygen. The CO-adsorbed Pt(111) surface is hydrophobic, as evidenced by the fact that water forms a complex with CO during evaporation of crystallites at 160-165 K. A disordered 2D layer remains on pristine $\mathrm{Pt}(111)$ up to $175 \mathrm{~K}$, whereas an ordered $2 \mathrm{D}$ layer exhibiting the $(\sqrt{ } 3 \times \sqrt{3}) R 30^{\circ}$ structure formed on oxygenated $\mathrm{Pt}(111)$ up to $200 \mathrm{~K}$.
\end{abstract}

\section{Introduction}

Interfacial water is ubiquitous in nature and plays an important role in fundamental research and technological applications. Interactions of water with solid surfaces have been studied extensively at cryogenic temperatures in terms of wettability, chemical reaction, crystallization kinetics, etc. $^{1,2}$ A considerable attention has been focused on water monolayers formed on close packed transition metal substrates because their lateral lattice parameter matches well with that of crystalline ices. A commensurate hexagonal ice bilayer, analogous to the (0001) plane of hexagonal ice $\mathrm{Ih}$, is expected to form an ordered $(\sqrt{ } 3 \times \sqrt{ } 3) R 30^{\circ}$ structure, as was observed in low energy electron diffraction (LEED). ${ }^{1,2}$ However, the structure of thin crystalline ice films on a Pt(111) substrate is still controversial. In contrast to the conventional picture, it was depicted based on X-ray absorption measurements that all water molecules in the first layer bind directly to the Pt(111) surface via alternating metal-oxygen and metal-hydrogen bonds, thereby forming a flat H-down water monolayer. ${ }^{3}$ It was also revealed using helium atom scattering $(\mathrm{HAS})^{4}$ and LEED $^{5}$ that ordered 2D domains exhibiting $(\sqrt{ } 37 \times \sqrt{ } 37) R 25^{\circ}$ and $(\sqrt{ } 39 \times \sqrt{ } 39) R 16^{\circ}$ structures formed via a slow deposition of water molecules at a temperature of $c a .130 \mathrm{~K}$;

\footnotetext{
${ }^{a}$ Transmission Electron Microscopy Station, National Institute for Materials Science, 1-2-1 Sengen, Tsukuba, Ibaraki 305-0047, Japan

${ }^{b}$ Center for Functional Sensor \& Actuator, National Institute for Materials Science, 1-1 Namiki, Tsukuba, Ibaraki 305-0044, Japan
}

water forms hexagonal structures connected by pentagonal and heptagonal units, as imaged using scanning tunneling microscopy (STM). ${ }^{6}$ Although the water molecule does not dissociate on $\operatorname{Pt}(111),{ }^{1,2,7}$ or does so in very small amounts, ${ }^{8}$ the $(\sqrt{ } 3 \times \sqrt{ } 3) R 30^{\circ}$ LEED pattern might be induced by chemisorbed $\mathrm{O}$ and $\mathrm{OH}$ species formed via electron-beam damage. ${ }^{9}$ In fact, a partially dissociated, hydrogen-bonded network of water exhibiting the $(\sqrt{ } 3 \times \sqrt{ } 3) R 30^{\circ}$ structure is known to be formed on a chemically more reactive substrate like $\mathrm{Ru}(0001) .{ }^{10}$ Consequently, it is likely that water forms a range of different hydrogen bonded clusters or networks on the $\operatorname{Pt}(111)$ surface, ${ }^{7}$ depending on the surface chemical reactivity that can be modified by a small amount of adspecies rather than the simple lattice parameter matching. At higher water coverage, continuous ice films can be formed on Pt(111): LEED $I-V$ analyses revealed that crystalline films thicker than $c a$. 40-50 layers exhibited a $(1 \times 1)$ termination of ice $\operatorname{Ih}(0001) .{ }^{11}$ To date, crystallization kinetics has also been explored using thin films of amorphous solid water (ASW) based on many other experimental techniques, such as isothermal desorption, ${ }^{12-15}$ temperature programmed desorption (TPD),${ }^{15-20}$ reflection high energy electron diffraction (RHEED), ${ }^{21-24}$ and reflection absorption infrared spectroscopy (RAIRS), ${ }^{19,25,26}$ together with the glass-liquid transition of $\mathrm{ASW}^{27,28}$ and premelting of crystalline ice ${ }^{28,29}$ based on time-of-flight secondary ion mass spectrometry (TOF-SIMS) and RHEED. In contradiction to the conventional picture of the ice Ih growth, it was revealed that ice Ic was formed preferentially on both hydrophilic and hydrophobic substrates based on the RHEED studies. ${ }^{21-24}$ 
The discrepancy might be related to the fact that small $3 \mathrm{D}$ crystallites descended from thinner ASW films can be analyzed by RHEED, in contrast to LEED that sees only top surfaces of wide spreads of 2D water layers and flat crystal grains. In this respect, RHEED is a much more powerful technique than LEED for studying nucleation and growth processes of crystalline ices.

In this paper, we investigate the interactions of water with the Pt(111) substrate and the influence of adspecies to gain insight into how the crystallization kinetics and wetting of thin films are controlled by the interfacial properties. To this end, crystallization and dewetting kinetics of ASW on pristine, oxygenated, and CO-adsorbed $\mathrm{Pt}(111)$ substrates are explored especially in the monolayer regime by using RHEED, TOF-SIMS, and TPD as a function of substrate temperature. The structure and quality of crystalline ices formed by heating the initial ASW films are compared with those formed via water vapor deposition at $135 \mathrm{~K}$ based on the RHEED image.

\section{Experiment}

Experiments were performed in an ultrahigh vacuum (UHV) chamber (base pressure of $2 \times 10^{-10}$ Torr) equipped with facilities of TOF-SIMS, RHEED and TPD. For TOF-SIMS measurements, a primary beam of $2 \mathrm{keV} \mathrm{He}^{+}$ions was generated in a differentiallypumped electron-impact-type ion source (Specs GmbH, IQE 12/38); the ion beam was chopped into pulses using electrostatic deflectors. A bias voltage $(+500 \mathrm{~V})$ was applied to the sample surface, and a removable mesh plate (grounded) was placed in front of the sample to extract low-energy secondary ions efficiently. Positive secondary ions were detected using a microchannel plate after passing through a field-free TOF tube. TOF spectra were recorded every $30 \mathrm{~s}$ using a multichannel scaler (Laboratory Equipment Inc., LN-6500R). The fluence of $\mathrm{He}^{+}$was kept below $1 \times 10^{12}$ ions $\mathrm{cm}^{-2}$ (sample current of $\sim 0.1 \mathrm{nA} \mathrm{cm}^{-2}$ ) to minimize degradation of thin films. To obtain RHEED patterns, a focused high-energy electron beam (30 keV) was generated in an electron gun (Eiko Co. Ltd, MB-1000). The diffraction pattern on a phosphor screen was recorded using a high-sensitivity CCD camera intermittently (duration of $\sim 0.5 \mathrm{~s}$ ) only at a specific temperature and coverage of interest to reduce the sample damage. TPD spectra were obtained using a differentially-pumped quadrupole mass analyzer (Hiden Analytical Ltd, IDP 300S). Temperature-programmed measurements were performed at a ramping speed of $5 \mathrm{~K} \mathrm{~min}^{-1}$.

A mirror-finished $\mathrm{Pt}(111)$ substrate was spot-welded to a sample holder made of Ta. The substrate was heated to $\sim 1500 \mathrm{~K}$ by electron bombardment from behind. Contaminants were removed via several $\mathrm{Ar}^{+}$-sputtering and annealing cycles. Cooling of the sample was achieved by means of a closed-cycle helium refrigerator. The substrate temperature was controlled using a cartridge heater by monitoring the temperature of the cold finger close to the sample position using $\mathrm{Au}(\mathrm{Fe})$-chromel thermocouples. Liquid water was degassed before use via several freeze-pump-thaw cycles. The $\mathrm{H}_{2} \mathrm{O}$ vapor and research-grade $\mathrm{O}_{2}$ and $\mathrm{CO}$ gases were admitted into the UHV chamber through precision variable leak valves. Cleanliness of the $\operatorname{Pt}(111)$ substrate with and without adspecies was ascertained based on the TOF-SIMS spectra. Regarding the ASW film thickness, the $\mathrm{H}^{+}$and $\mathrm{H}_{3} \mathrm{O}^{+}$intensities in TOF-SIMS were saturated at exposure to 2-3 langmuirs $\left(1 \mathrm{~L}=1 \times 10^{-6}\right.$ Torr s) at $100 \mathrm{~K},{ }^{29}$ where the first monolayer is expected to be formed. However, the sticking probability of water is likely to depend on the surface chemical properties and substrate temperature. In this paper, therefore, the films were characterized by water exposure rather than the exact coverage.

\section{Experimental results}

Fig. 1 shows (a) temperature-programmed TOF-SIMS intensities and (b) a TPD spectrum obtained using the ASW film prepared by deposition of $2 \mathrm{~L}$ water onto the $\mathrm{Pt}(111)$ substrate at $100 \mathrm{~K}$ (under a $\mathrm{H}_{2} \mathrm{O}$ backfilling pressure of $1 \times 10^{-8}$ Torr). Upon adsorption of water, not only $\mathrm{H}^{+}$and $\mathrm{H}^{+}\left(\mathrm{H}_{2} \mathrm{O}\right)_{n}$ ions, but also ion adducts in the form of $\mathrm{Pt}^{+}\left(\mathrm{H}_{2} \mathrm{O}\right)_{n}$ were emitted. ${ }^{29}$ Stepwise decreases are observed in the $\mathrm{H}^{+}$and $\mathrm{H}_{3} \mathrm{O}^{+}$intensities at 150, 160 , and $170 \mathrm{~K}$. The TPD spectrum exhibits a double-peak structure, corresponding to desorption from 3D (163 K) and $2 \mathrm{D}(170 \mathrm{~K})$ domains of water on $\mathrm{Pt}(111) .{ }^{30,31}$ All secondary ions decay at $170 \mathrm{~K}$ along with the occurrence of the 2D peak in TPD. The first steps of $\mathrm{H}^{+}$and $\mathrm{H}_{3} \mathrm{O}^{+}$intensities at $150 \mathrm{~K}$ are ascribable to film dewetting during water crystallization (see the RHEED patterns described later). The second steps at $160 \mathrm{~K}$ result from desorption of crystallites, as manifested by the $3 \mathrm{D}$ peak in TPD. In contrast to $\mathrm{H}^{+}$and $\mathrm{H}_{3} \mathrm{O}^{+}$ions, the $\mathrm{Pt}^{+}\left(\mathrm{H}_{2} \mathrm{O}\right)_{2}$ ion survives considerably after disappearance of crystallites, because it is emitted preferentially

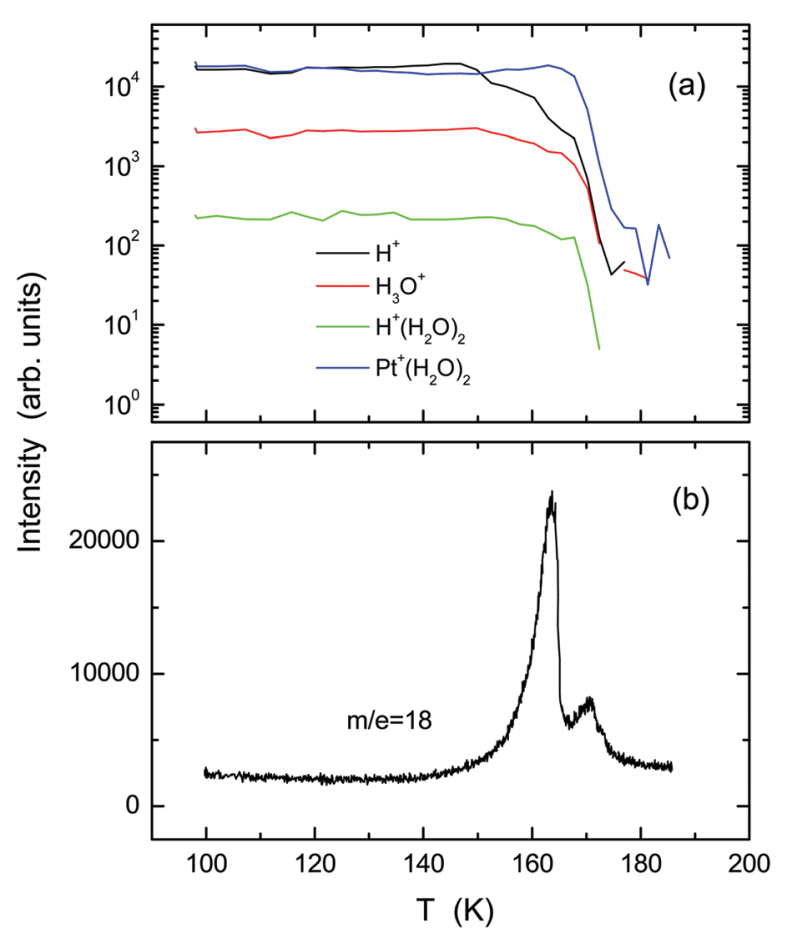

Fig. 1 Temperature-programmed TOF-SIMS intensities (a) and the TPD spectrum (b) obtained using the ASW film formed on the $\mathrm{Pt}(111)$ substrate. The film was formed by exposure to $2 \mathrm{~L} \mathrm{H}_{2} \mathrm{O}$ molecules at $100 \mathrm{~K}$; then, the substrate temperature was increased at a rate of $5 \mathrm{~K} \mathrm{~min}^{-1}$. 
from monolayer domains of water in direct contact with the $\mathrm{Pt}(111)$ substrate (i.e., the 2D layer). Note that a characteristic shoulder in TPD, which is known as a sign of crystallization of the multilayer ASW films, ${ }^{16,18}$ is not recognized at around $150 \mathrm{~K}$.

Upon heating above $150 \mathrm{~K}$, the ASW film becomes inhomogeneous because of the growth of crystal grains. Their structure and epitaxial relationship with respect to the substrate are determined based on RHEED. Images taken along the [11̄̄] azimuth of the substrate are presented in Fig. 2. For the pristine $\mathrm{Pt}(111)$ surface (a), intense diffraction rods are recognizable in the zero-order and first-order Laue zones. After deposition of $2 \mathrm{~L} \mathrm{H}_{2} \mathrm{O}$ molecules at $100 \mathrm{~K}$ (b), the rods from the $\mathrm{Pt}(111)$ substrate are weakened and diffuse scattering from ASW appears. The diffuse pattern is maintained fundamentally up to $140 \mathrm{~K}$. Then, sharp streaks and Bragg spots characteristic of the crystalline ice are identifiable at temperatures of (c) 150, (d) 155, and (e) $160 \mathrm{~K}$. No diffraction patterns other than those from the clean $\mathrm{Pt}(111)$ substrate are obtained at $165 \mathrm{~K}$ (f), indicating that the 2D layer formed immediately after evaporation of crystallites is not ordered.

It is expected that the (111) oriented ice Ic or the (0001) oriented ice Ih are grown on the Pt(111) substrate. Simulated RHEED patterns for the ices Ih and Ic, respectively, are shown in the left and right halves of Fig. 3(b), together with the indexed RHEED image in Fig. 3(a). The streaky RHEED patterns, which is close to the $\operatorname{Pt}(111)(\sqrt{ } 3 \times \sqrt{ } 3) R 30^{\circ}$ periodicity, are basically ascribable to the ice crystallite. They consist of elongated
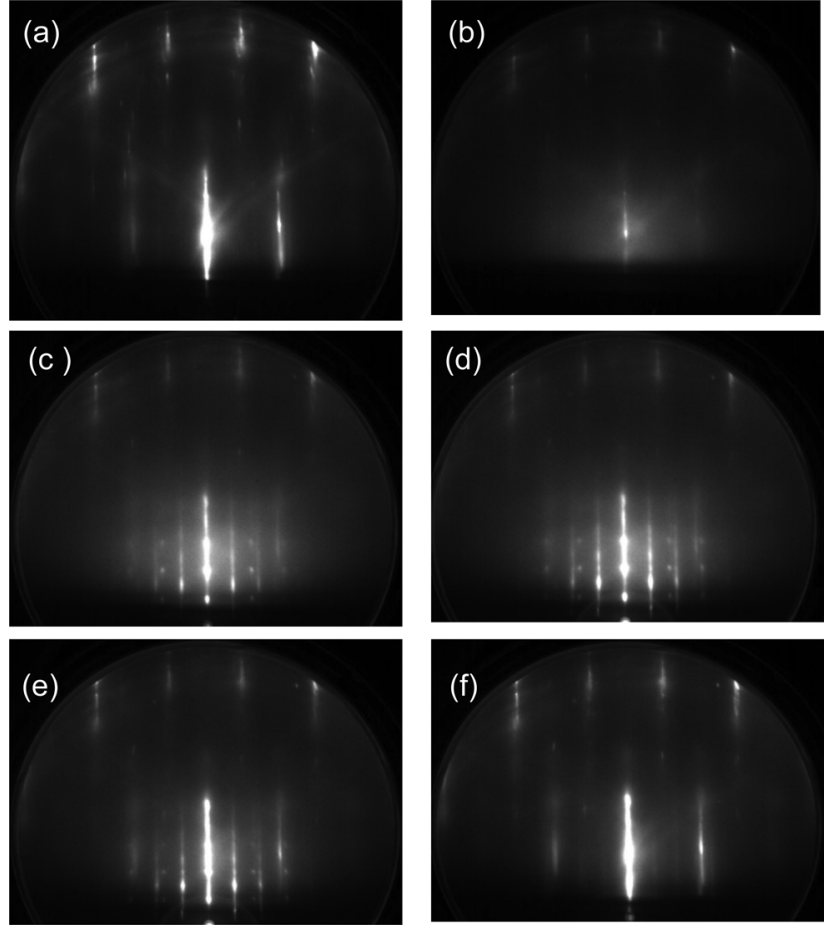

Fig. 2 RHEED images of the pristine Pt(111) substrate (a) and the wateradsorbed $\mathrm{Pt}(111)$ substrate with increasing temperature (b-f). The ASW film was formed by deposition of $2 \mathrm{~L}$ water at $100 \mathrm{~K}$; images obtained at temperatures of (b) 100, (c) 150, (d) 155, (e) 160 , and (f) $165 \mathrm{~K}$ are displayed. They were taken along the [11-2] azimuth of Pt(111).

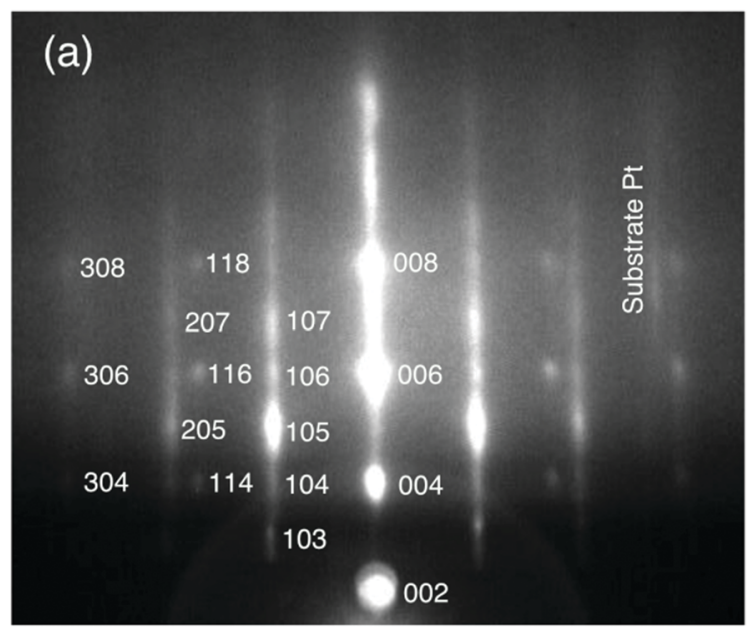

(b)

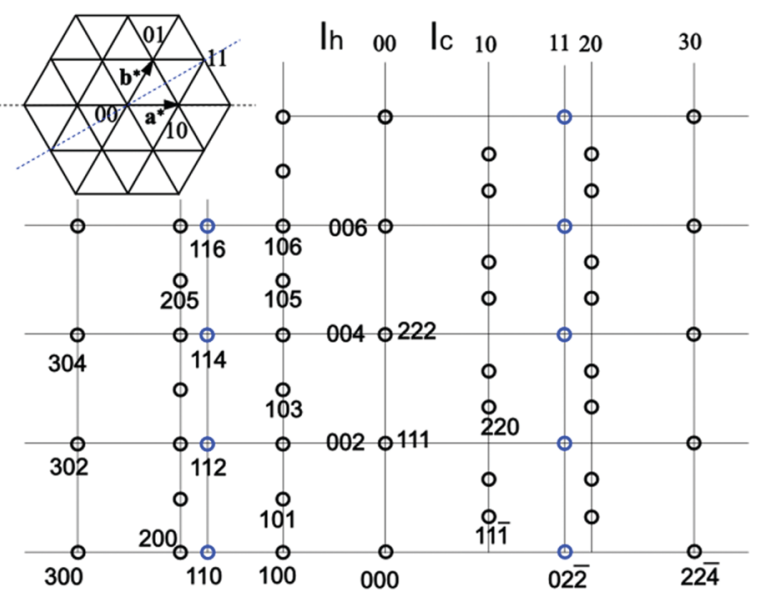

Fig. 3 (a) The diffraction spots for the RHEED pattern in Fig. 2(d) are indexed. (b) The simulated RHEED patterns for the epitaxial Ih (left half) and Ic (right half) ice crystallites. The ices Ih and Ic are distinguishable because they give distinct spots on the 10 and 20 rods.

Bragg spots because ice Ic and Ih structures coexist, specifically, the occurrence of stacking disorder in the basal planes. ${ }^{32}$ Additional sharp spots assigned as 114, 116, and 118 in Fig. 3(a) are attributable to crystallites grown in the other azimuthal direction, i.e., $\pm 30^{\circ}$ off relative to those yielding the $(\sqrt{ } 3 \times \sqrt{ } 3) R 30^{\circ}$-like pattern. In this azimuth, the sharp spots of 3D crystallites are observed instead of the streaks because the Ic and Ih crystallites make spots at the same position. From these facts, the streaky patterns are better ascribable to the 3D grains of mixed ices Ic and Ih, or a stacking disordered ice, rather than a flat terrace of large ice Ih grains. This interpretation is compatible with the occurrence of dewetting (i.e., water aggregation to form 3D grains) during crystallization of the ASW film (Fig. 1(a)). The streaks underlying the Bragg spots suggest that crystal grains have a flat terrace or an ordered 2D water lattice coexists. The latter is discarded from the fact that streaks disappear after evaporation of crystallites, as seen in Fig. 2(f).

Fig. 4 shows (a) temperature-programmed TOF-SIMS intensities and (b) TPD spectra obtained using the ASW film (2 L) formed on an oxygen-adsorbed $\mathrm{Pt}(111)$ substrate at $100 \mathrm{~K}$. For oxygenation, 


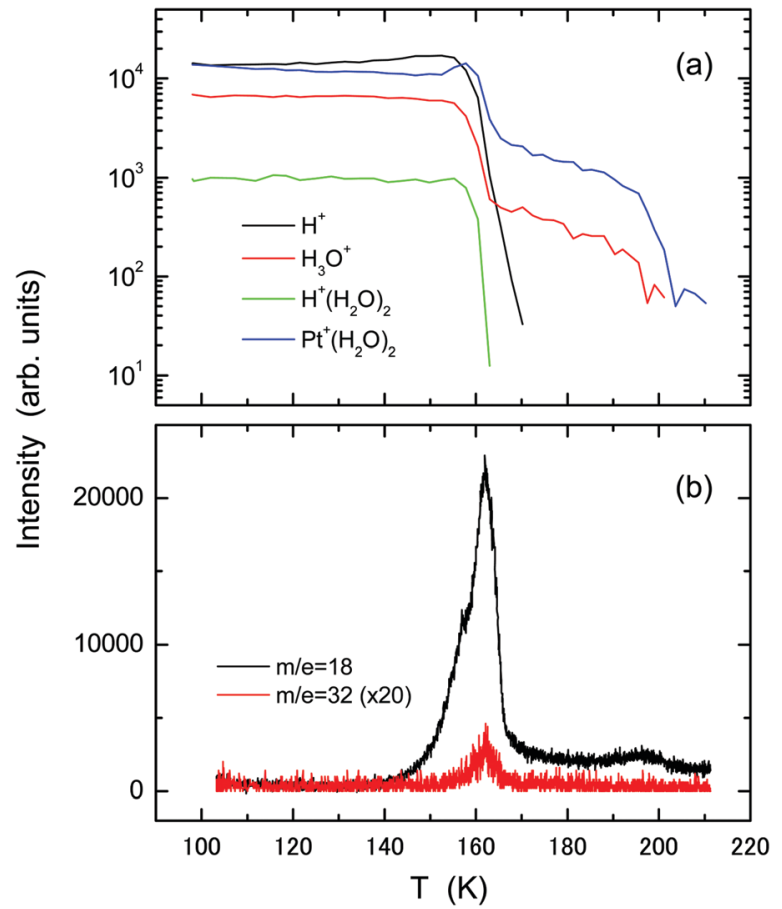

Fig. 4 The same as in Fig. 1, but using the oxygenated Pt(111) substrate prepared by exposure to $5 \mathrm{~L} \mathrm{O}_{2}$ molecules at $100 \mathrm{~K}$.

the $\mathrm{Pt}(111)$ substrate was exposed to $5 \mathrm{~L} \mathrm{O}_{2}$ molecules at $100 \mathrm{~K}$. Most of the $\mathrm{O}_{2}$ species are adsorbed molecularly under this condition as confirmed by high-resolution electron energy loss spectroscopy (HREELS). ${ }^{33-35}$ In contrast to the result obtained using the pristine $\mathrm{Pt}(111)$ substrate, TOF-SIMS exhibits no steps ascribable to film morphology change in the $\mathrm{H}^{+}$and $\mathrm{H}_{3} \mathrm{O}^{+}$ intensities. The increase in the $\operatorname{Pt}^{+}\left(\mathrm{H}_{2} \mathrm{O}\right)_{2}$ intensity at $T>153 \mathrm{~K}$ results from film dewetting and/or evaporation of water. The TPD spectrum of water exhibits a main peak at around $162 \mathrm{~K}$, where the $\mathrm{H}^{+}$and $\mathrm{H}^{+}\left(\mathrm{H}_{2} \mathrm{O}\right)_{2}$ intensities also decay in TOF-SIMS. The intact $\mathrm{O}_{2}$ molecules desorb together with water. The $\mathrm{O}_{2}$ TPD peak appears at higher temperature than that from $\mathrm{O}_{2}$ adsorbed $\mathrm{Pt}(111)(\sim 140 \mathrm{~K}),{ }^{35}$ suggesting the occurrence of some attractive interaction between $\mathrm{O}_{2}$ and water. The $\mathrm{O}_{2}$ peak is considerably small, suggesting that the chemisorbed $\mathrm{O}$ species are formed on the surface during the heating process. The $\mathrm{H}_{3} \mathrm{O}^{+}$and $\mathrm{Pt}^{+}\left(\mathrm{H}_{2} \mathrm{O}\right)_{2}$ ions remain up to $200 \mathrm{~K}$ where a small peak appears in water TPD, signifying the presence of water residues. This peak corresponds to the $2 \mathrm{D}$ peak observed at $170 \mathrm{~K}$ using the pristine Pt(111) substrate, but it appears at higher temperature because water molecules are bound tightly to the chemisorbed oxygen species. ${ }^{36}$ A small shoulder in the water TPD spectrum at around $157 \mathrm{~K}$ is ascribable to water crystallization. ${ }^{16,18}$

The influence of oxygen adspecies on the crystallization kinetics of ASW is also investigated based on the diffraction pattern. Fig. 5 presents RHEED images obtained during the heating process of the ASW film prepared in the same way as in Fig. 4. The RHEED image obtained by deposition of $5 \mathrm{~L} \mathrm{O}_{2}$ molecules at $100 \mathrm{~K}$ (a) is almost unchanged relative to that using the bare Pt(111) substrate. The diffuse RHEED pattern of
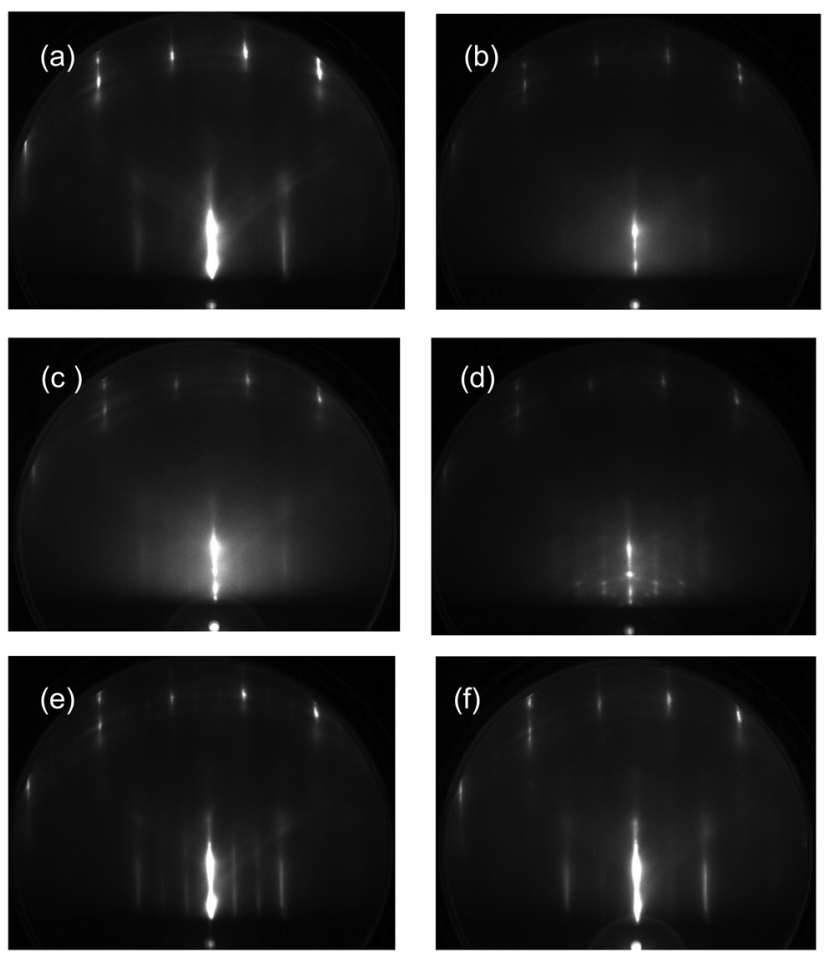

Fig. 5 (a) The RHEED image obtained using the oxygenated Pt(111) substrate. The ASW film was formed on it by deposition of $2 \mathrm{~L}$ water at $100 \mathrm{~K}$; images obtained during the heating process at (b) 100 , (c) 150 , (d) 160 , (e) 180 , and (f) $200 \mathrm{~K}$ are displayed.

ASW appears after exposure to $2 \mathrm{~L}$ water (b). The pattern is fundamentally unchanged up to $150 \mathrm{~K}$ (c). The crystallites are formed at around $160 \mathrm{~K}$ (d), as confirmed from the occurrence of Bragg spots. It is revealed from the diffraction pattern that ice Ic is formed preferentially although the spots are rather vague in comparison with those of ice Ih formed on the pristine $\mathrm{Pt}(111)$ substrate in Fig. 2. Additional spots between the original spots of ice Ic are ascribable to the formation of twins, and a weak Debye-Scherrer ring is also identifiable. The $(\sqrt{ } 3 \times \sqrt{ } 3) R 30^{\circ}$ structure formed at $180 \mathrm{~K}$ after evaporation of crystallites (e), indicating that water residues tend to be ordered on oxygenated Pt(111). The RHEED pattern changes to a weak $2 \times 2$ structure along with the desorption of residual water at $200 \mathrm{~K}$ (f) because the chemisorbed oxygen finally forms the ordered structure. ${ }^{33}$ The crystallization kinetics of ASW is fundamentally unchanged when the film is deposited onto the substrate exhibiting the $(\sqrt{ } 3 \times \sqrt{ } 3) R 30^{\circ}$ pattern (not shown), suggesting that the presence of chemisorbed oxygen rather than its initial structure plays a role in controlling the epitaxial growth of the crystalline ice.

Fig. 6 presents experimental results of (a) TOF-SIMS and (b) TPD obtained using the ASW film (2 L) deposited at $100 \mathrm{~K}$ onto the $\mathrm{Pt}(111)-\mathrm{CO}$ substrate which is formed by adsorption of $5 \mathrm{~L}$ $\mathrm{CO}$ at $150 \mathrm{~K}$. With increasing temperature, intensities of the $\mathrm{H}^{+}$and $\mathrm{Pt}^{+}\left(\mathrm{H}_{2} \mathrm{O}\right)_{2}$ ions decrease gradually. The intensity of $\mathrm{H}^{+}\left(\mathrm{H}_{2} \mathrm{O}\right)_{2}$ rather increases relative to $\mathrm{H}_{3} \mathrm{O}^{+}$during desorption of water molecules at $T=160-165 \mathrm{~K}$. No independent TPD peak from the $2 \mathrm{D}$ water layer is identifiable, in agreement with decay of the $\mathrm{Pt}^{+}\left(\mathrm{H}_{2} \mathrm{O}\right)_{2}$ intensity, but a small tail exists up to $180 \mathrm{~K}$, 


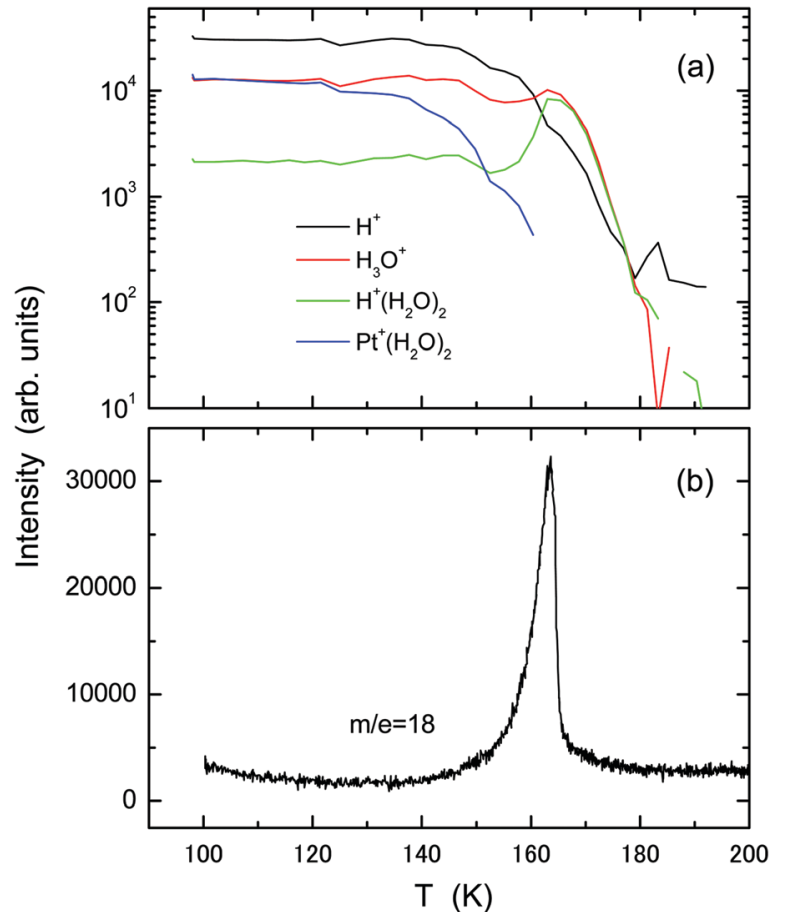

Fig. 6 The same as in Fig. 1, but using the CO-adsorbed Pt(111) substrate prepared by exposure to $5 \mathrm{~L} \mathrm{CO}$ molecules at $150 \mathrm{~K}$.

corresponding to the secondary ions from residues. The results contrast significantly to those using the pristine and oxygenated $\mathrm{Pt}(111)$ substrates.

The temperature-programmed RHEED images obtained using the ASW film $(2 \mathrm{~L})$ formed on the CO-adsorbed $\mathrm{Pt}(111)$ substrate are shown in Fig. 7. Additional streaks appear upon CO deposition (a). CO adsorbs molecularly on Pt(111),,$^{37,38}$ although complicated structures are known to occur depending on its coverage. The adsorption sites of $\mathrm{CO}$ are still controversial between experiment and theory. ${ }^{38}$ In this study, therefore, no detailed structure of CO-adsorbed $\mathrm{Pt}(111)$ is discussed. The diffuse diffraction pattern of the ASW film (b) is different from the spotty patterns of crystallites at $150 \mathrm{~K}$ (c) and $155 \mathrm{~K}$ (d). The diffraction spots are streaky because of the coexistence of Ic and Ih crystallites or the formation of a stacking disordered ice. ${ }^{32}$ The sharp spots inside the second rods come from crystallites with other orientations. The Bragg spots are weakened considerably at $160 \mathrm{~K}(\mathrm{e})$, and no diffraction spots from adsorbed water are recognizable at $165 \mathrm{~K}$ (f) after evaporation of crystallites (see the TPD spectrum in Fig. 6(b)). However, even after evaporation of ice crystallites, the $\mathrm{H}_{3} \mathrm{O}^{+}$and $\mathrm{H}^{+}\left(\mathrm{H}_{2} \mathrm{O}\right)_{2}$ ions have considerable intensity at $165 \mathrm{~K}$ (Fig. 6(a)), suggesting that water residues adsorb disorderly on the CO-adsorbed Pt(111) surface, or less probably, the CO-water composite layer provides a commensurate lattice to the substrate.

In the above context, water crystallization has been explored by heating the initial ASW films. The crystalline ice can be formed via vapor deposition when the surface diffusivity of water is kept sufficiently high. RHEED patterns obtained during water deposition at $135 \mathrm{~K}$ (close to the water's glass transition
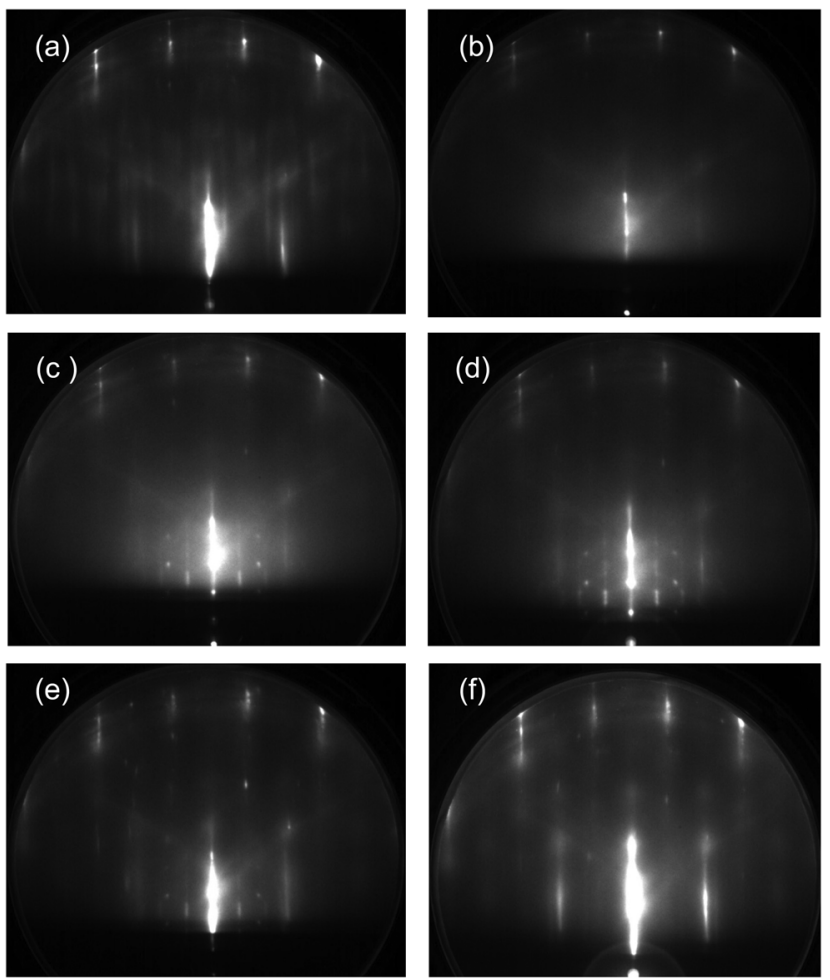

Fig. 7 (a) The RHEED image obtained using the CO-adsorbed Pt(111) substrate. The ASW film was formed on it by deposition of $2 \mathrm{~L}$ water at $100 \mathrm{~K}$; images obtained during the heating process at (b) 100 , (c) 150 , (d) 155 , (e) 160 , and (f) $165 \mathrm{~K}$ are displayed.

temperature of $\left.T_{\mathrm{g}}=136 \mathrm{~K}\right)^{17,39}$ are shown in Fig. 8. When the pristine Pt(111) substrate is used, streaky diffraction patterns of ice Ih are obtained after exposure to (a) 2 and (b) $20 \mathrm{~L}$ water. No additional spots from crystallites with other orientations are present in contrast to those descended from ASW (Fig. 2). It is known that Debye-Scherrer ring patterns are observed when thicker ASW films (15-20 L) are crystallized because randomly oriented crystallites are formed. ${ }^{24,29}$ However, ordered crystallites continue to grow till considerably high exposures during hightemperature water deposition because the ice is grown homoepitaxially on smaller grains (i.e., nuclei) formed initially. It is thus suggested that the epitaxial growth occurs more preferentially during slow water-vapor deposition at around $T_{\mathrm{g}}$ rather than the nucleation and growth process of the initial ASW films occurring at around $150 \mathrm{~K}$. The RHEED patterns in Fig. 8(c and d), respectively, are obtained during deposition of 2 and $20 \mathrm{~L}$ water molecules onto the oxygenated $\operatorname{Pt}(111)$ substrate that initially exhibited the $(\sqrt{ } 3 \times \sqrt{ } 3) R 30^{\circ}$ pattern. In this case, the ice Ic crystallites are formed predominantly. The Debye-Scherrer ring pattern is weakened in comparison with that in Fig. 5(d) even for the thicker film. However, crystallinity of the film is apparently poor compared to that formed on the pristine $\mathrm{Pt}(111)$ substrate. During water vapor deposition on the CO-adsorbed Pt(111) substrate, the ice Ic crystallite is grown initially at exposure to $2 \mathrm{~L}$ water (e), which is followed by the growth of ice Ih after exposure to $20 \mathrm{~L}$ (f). The RHEED patterns of ice formed on the CO-adsorbed Pt(111) substrate (e and f) are spottier than those obtained using 

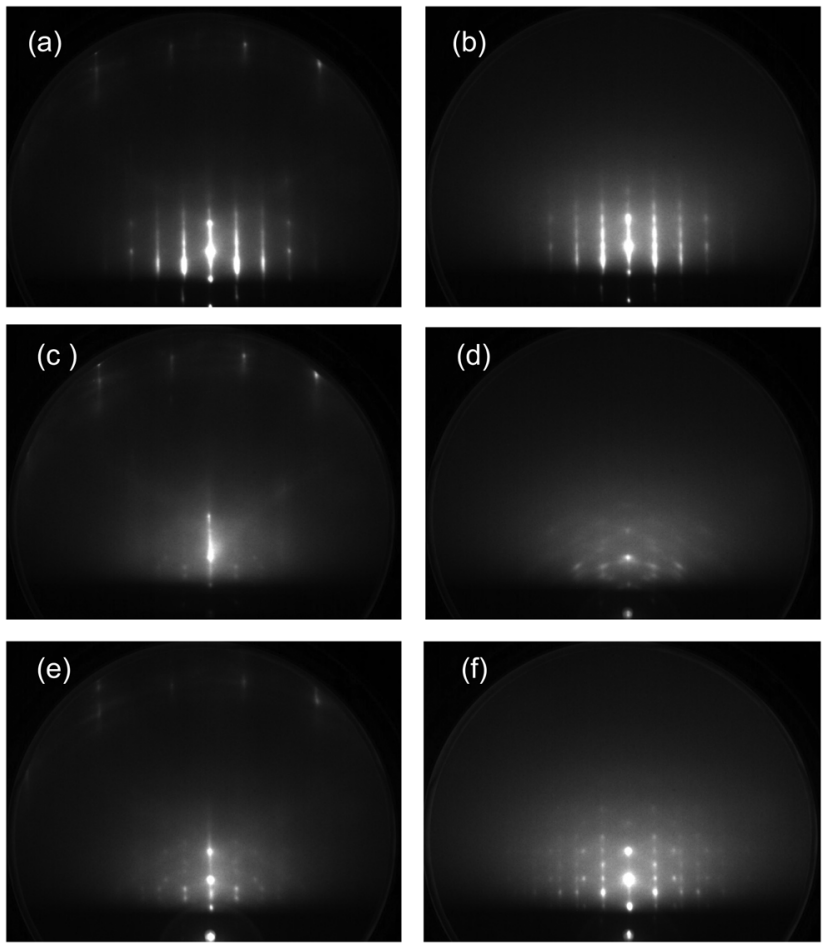

Fig. 8 RHEED images of crystalline ices formed by water vapor deposition onto the pristine ( $a$ and b), oxygenated ( $c$ and d), and CO-adsorbed (e and f) Pt(111) substrates at $135 \mathrm{~K}$. The mages obtained by water exposure to $2 \mathrm{~L}(\mathrm{a}, \mathrm{c}$ and e) are compared with those of $20 \mathrm{~L}(\mathrm{~b}, \mathrm{~d}$ and $\mathrm{f}$ ).

the pristine $\mathrm{Pt}(111)$ substrate (a and b), suggesting the growth of larger 3D crystallites. Consequently, the effect of CO adspecies is apparently weak relative to that of chemisorbed oxygen in terms of the epitaxial growth of crystalline ices on $\mathrm{Pt}(111)$.

\section{Discussion}

The crystallization kinetics of thin ASW films, as well as the water-Pt interactions, are influenced strongly by the oxygen adspecies on the $\operatorname{Pt}(111)$ substrate. The nucleation temperature of water becomes higher (155-160 K), as revealed from both the RHEED pattern and film morphology change. Probably, reorganization of water molecules to create nuclei at the substrate interface is disturbed when the hydrogen bonds are formed with the chemisorbed oxygen. Consequently, the water crystallization temperature approaches to the spontaneous nucleation temperature of bulk water $(\sim 160 \mathrm{~K})^{39}$ using the oxygenated $\mathrm{Pt}(111)$ substrate. The ice Ic is formed preferentially instead of ice Ih with the epitaxial relationship of $(111)_{\mathrm{Ic}} / /(111)_{\mathrm{Pt}}$ and $[1 \overline{1} 0]_{\mathrm{Ic}} / /[11 \overline{2}]_{\mathrm{Pt}}$. Along with this behavior, the characteristic shoulder during crystallization becomes identifiable in the water TPD spectrum. The desorption rate of water molecules is associated with the film morphology change, so that the TPD shoulder might be hindered when the crystal grains are created gradually via the substrate induced nucleation at lower temperatures than the spontaneous nucleation. After evaporation of crystallites, the 2D layer remains on the oxygenated $\mathrm{Pt}(111)$ surface till higher temperature $(\sim 200 \mathrm{~K})$ than using the pristine $\operatorname{Pt}(111)$ substrate. This behavior is ascribable either to the formation of hydrogen bonds between water and chemisorbed oxygen atoms or to the dissociative adsorption of water molecules to form hydroxyl groups. The former is not sufficient to make water residues adsorb up to $200 \mathrm{~K}$, as evidenced by the result for water adsorption on a hydroxylated Si substrate. ${ }^{18}$ It is well established that water is dissociated by chemisorbed oxygen on $\mathrm{Pt}(111) .{ }^{1,2}$ However, the $\mathrm{H}_{3} \mathrm{O}^{+}$and $\mathrm{Pt}^{+}\left(\mathrm{H}_{2} \mathrm{O}\right)_{2}$ ions are emitted from the 2D layer, which suggests that water residues are not dissociated completely. The experimental result using the oxygenated Pt(111) substrate resembles that of the water monolayer formed on the pristine $\mathrm{Ru}(0001)$ substrate, where water molecules are partially dissociated. ${ }^{10}$ The strong suppression of the $\mathrm{H}^{+}$yield relative to $\mathrm{H}_{3} \mathrm{O}^{+}$in Fig. 4(a) is explainable as that the hydroxyl group of water tends to be directed towards the substrate or parallel to the surface via the formation of hydrogen bonds with the chemisorbed oxygen atoms. The partially dissociated water species are pinned at the chemisorbed oxygen sites, thereby formation of the $(\sqrt{3} \times \sqrt{ } 3) R 30^{\circ}$ structure for the $2 \mathrm{D}$ layer on the oxygenated $\mathrm{Pt}(111)$ substrate. In contrast, the 2D layer of intact water formed on the pristine $\operatorname{Pt}(111)$ substrate is not ordered at higher temperatures because of the absence of hydrogen bonding with the substrate. The water molecule in direct contact with the substrate behaves like a liquid that is equilibrated with the premelting layer of crystallites. ${ }^{28,29,40}$ The liquidlike 2D layer is expected to be ordered by cooling. Probably, such water species form hexagonal rings both in registry and out-of-registry with the substrate atoms, as imaged by STM at lower temperatures. ${ }^{6,41}$

The nucleation temperature of water on CO-adsorbed $\operatorname{Pt}(111)$ is basically the same as that on pristine $\operatorname{Pt}(111)$. The lack of the shoulder in the water TPD spectrum is also consistent with this behavior. The RHEED pattern from crystallites becomes spottier than that using pristine Pt(111), and stacking disorders are formed considerably. It should be noticed that the $\mathrm{H}^{+}\left(\mathrm{H}_{2} \mathrm{O}\right)_{2}$ ions increase in intensity after crystallization occurs at $c a .150 \mathrm{~K}$. The enhancement of cluster ion intensities during sputtering has been reported for water adsorbed on a hydrogenated $\mathrm{Pt}(111)$ substrate, ${ }^{42}$ but the present result has nothing to do with this phenomenon. The decrease in the $\operatorname{Pt}^{+}\left(\mathrm{H}_{2} \mathrm{O}\right)_{2}$ intensity at $T>130 \mathrm{~K}$ in Fig. 6(a) strongly suggest that water molecules tend to interact with $\mathrm{CO}$ on the $\mathrm{Pt}(111)$ substrate along with weakening of the water-Pt interaction at higher temperatures. Consequently, the $\mathrm{Pt}(111)$ substrate becomes hydrophobic upon adsorption of $\mathrm{CO}$ molecules. It is known that cluster ions, $\mathrm{H}^{+}\left(\mathrm{H}_{2} \mathrm{O}\right)_{n}$, are emitted efficiently via an electronic sputtering process when water is adsorbed on molecular solid films because of the localization of ionic holes or the occurrence of "Coulomb explosion" of water nanoclusters. ${ }^{43}$ The smaller the cluster size is, the more efficiently cluster ions are emitted. The same is expected to occur when "potential sputtering", occurs using the primary $\mathrm{He}^{+}$ions. ${ }^{44}$ Probably, this is a reason why the $\mathrm{H}^{+}\left(\mathrm{H}_{2} \mathrm{O}\right)_{2}$ ion increases in intensity after evaporation of crystallites at $162 \mathrm{~K}$ (Fig. 6). It is also possible that the CO adspecies undergoes "hydrophobic hydration". The fact that the $\mathrm{H}^{+}$intensity 
decreases relative to the $\mathrm{H}_{3} \mathrm{O}^{+}$intensity at $T>160 \mathrm{~K}$ might be ascribed to the formation of hydration shells of water whose $\mathrm{OH}$ group is direct towards the hydrophobic CO solute. Such a structure has been predicted to occur during interactions of water with hydrophobic species based on molecular dynamics simulations. ${ }^{45-47}$ Probably, this provides a reason why the water-CO interactions are attractive when water is physisorbed on a saturated CO monolayer on $\mathrm{Pt}(111) .{ }^{2}$ Consequently, the epitaxial growth of crystallites is realized more preferentially in the presence of the $\mathrm{CO}$ molecule rather than the chemisorbed oxygen because the former does not disturb the reorganization of hydrogen bonds during water nucleation at the substrate interface.

\section{Conclusions}

How the water molecules in the monolayer regime interact with oxygen and carbon-monoxide adspecies on Pt(111) was investigated in comparison with the results using the pristine $\mathrm{Pt}(111)$ substrate in terms of the crystallization kinetics and surface wettability. The ASW film on the Pt(111) surface crystallizes above $150 \mathrm{~K}$, thereby forming epitaxially-grown ice Ih grains and a disordered 2D layer. The latter survives up to $175 \mathrm{~K}$ after evaporation of crystallites at $165 \mathrm{~K}$. The ASW film crystallizes into ice Ic preferentially on the oxygenated $\mathrm{Pt}(111)$ substrate, where ordering of the crystallites with respect to the substrate is poor in comparison with that on the pristine Pt(111) substrate. The nucleation temperature increases as well because reorganization of water molecules to form nuclei is disturbed by hydrogen bonds with the chemisorbed oxygen. Such water species are dissociated partially and exhibit the $(\sqrt{ } 3 \times \sqrt{ } 3) R 30^{\circ}$ structure after disappearance of crystallites up to $200 \mathrm{~K}$. The stacking disordered ice or a mixture of Ic and Ih crystallites is formed on the CO-adsorbed Pt(111) substrate when ASW is heated to $150 \mathrm{~K}$. This substrate appears to be hydrophobic because the water-Pt contact is hampered with increasing temperature. The yield of water cluster ions increases during and after evaporation of crystallites, indicating that water residues interacting preferentially with the $\mathrm{CO}$ adspecies are sputtered efficiently because of the isolation from the metal substrate.

\section{Conflicts of interest}

There are no conflicts to declare.

\section{Acknowledgements}

This research was partly funded by the Japan Society for the Promotion of Science through a Grant-in-Aid for Scientific Research (C), No. 22540339.

\section{References}

1 P. A. Thiel and T. T. Madey, Surf. Sci. Rep., 1987, 7, 211.

2 M. A. Henderson, Surf. Sci. Rep., 2002, 46, 1.
3 H. Ogasawara, B. Brena, D. Nordlund, M. Nyberg, A. Pelmenschikov, L. G. M. Petterrsson and A. Nilsson, Phys. Rev. Lett., 2002, 89, 276102.

4 A. Glebov, A. P. Graham, A. Menzel and J. P. Toennies, J. Chem. Phys., 1997, 106, 9382.

5 S. Haq, J. Harnett and A. Hodgson, Surf. Sci., 2002, 505, 171. 6 S. Nie, P. J. Feibelman, N. C. Bartelt and K. Thrumer, Phys. Rev. Lett., 2010, 105, 026102.

7 A. Hodgson and S. Haq, Surf. Sci. Rep., 2009, 64, 381.

8 Y. Lilach, M. J. Iedama and J. P. Cowin, Phys. Rev. Lett., 2007, 98, 016105.

9 C. Clay, S. Haq and A. Hodgson, Phys. Rev. Lett., 2004, 92, 046102.

10 P. J. Feibelman, Science, 2002, 295, 99.

11 N. Materer, U. Starke, A. Barbieri, M. A. Van Hove, G. A. Somorjay, G.-J. Kroes and C. Minot, J. Phys. Chem., 1995, 99, 6267.

12 R. S. Smith, C. Huang, E. K. L. Wong and B. D. Kay, Surf. Sci., 1996, 367, L13.

13 P. Lofgren, P. Ahlstrom, D. V. Chakarov, J. Lausmaa and B. Kasemo, Surf. Sci., 1996, 367, L19.

14 P. Lofgren, P. Ahlstrom, J. Lausma, B. Kasemo and D. Chakarov, Langmuir, 2003, 19, 265.

15 S. M. McClure, E. T. Barlow, M. C. Akin, D. J. Safarik, T. M. Truskett and C. B. Mullins, J. Phys. Chem. B, 2006, 110, 17987.

16 R. S. Smith, C. Huang, E. K. L. Wong and B. D. Kay, Phys. Rev. Lett., 1997, 79, 909.

17 R. S. Smith, C. Huang and B. D. Kay, J. Phys. Chem. B, 1997, $101,6123$.

18 R. Souda, J. Phys. Chem. C, 2012, 116, 20895.

19 A. S. Bolina, A. J. Wolff and W. A. Brown, J. Phys. Chem. B, 2005, 109, 16836.

20 J. Günster and R. Souda, Langmuir, 2006, 22, 6939.

21 C.-Y. Ruan, V. A. Lobastov, F. Vigliotti, S. Chen and A. H. Zewail, Science, 2004, 304, 80.

22 D.-S. Yang and A. H. Zewail, Proc. Natl. Acad. Sci. U. S. A., 2009, 106, 4122.

23 X. He, C. Wu and D.-S. Yang, J. Chem. Phys., 2016, 145, 171102.

24 R. Souda and T. Aizawa, Phys. Chem. Chem. Phys., 2018, 20, 21856.

25 P. Jenniskens, S. F. Banham, D. F. Blake and M. R. S. McCoustra, J. Chem. Phys., 1997, 107, 1232.

26 E. H. G. Backus, M. L. Grecea, A. W. Kleyn and M. Bonn, Phys. Rev. Lett., 2004, 92, 236101.

27 R. Souda, Phys. Rev. Lett., 2004, 93, 235502.

28 R. Souda, J. Phys. Chem. C, 2017, 121, 12199.

29 R. Souda and T. Aizawa, J. Phys. Chem. C, 2018, 122, 28094. 30 S. Haq, J. Harnett and A. Hodgson, Surf. Sci., 2002, 505, 171. 31 G. A. Kimmel, N. G. Petrik, Z. Dohnalek and B. D. Kay, Phys. Rev. Lett., 2005, 95, 166102.

32 T. L. Malkin, B. J. Murray, A. V. Brukhno, J. Anwar and C. G. Salzmann, Proc. Natl. Acad. Sci. U. S. A., 2012, 109, 1041.

33 J. L. Gland and B. A. Sexton, Surf. Sci., 1980, 95, 587.

34 H. Steininger, S. Lehwald and H. Ibach, Surf. Sci., 1982, 123, 1. 35 N. R. Avery, Chem. Phys. Lett., 1983, 96, 371.

36 G. Zimbitas, M. E. Gallaghher, G. R. Darling and A. Hodgson, J. Chem. Phys., 2008, 128, 074701. 
37 H. Steininger, S. Lehwald and H. Ibach, Surf. Sci., 1982, 123, 264.

38 P. J. Feibelman, B. Hammer, J. K. Norskov, F. Wagner, M. Scheffler, R. Stumpf, R. Watwe and J. Dumesic, J. Phys. Chem. B, 2001, 105, 4018.

39 G. P. Johari, A. Hallbrucker and E. Mayer, Nature, 1987, 330, 552.

40 R. Souda, Phys. Chem. Chem. Phys., 2014, 16, 1095.

41 S. Maier, B. A. J. Lechner, G. A. Somorjai and M. Salmeron, J. Am. Chem. Soc., 2016, 138, 3145.
42 Y. Kim, S. Shin and H. Kang, Angew. Chem., Int. Ed., 2015, 26, 7626.

43 R. Souda, Phys. Rev. B: Condens. Matter Mater. Phys., 2002, 65, 245419.

44 R. Souda, J. Phys. Chem. A, 2007, 111, 201.

45 C. Y. Lee, J. A. McCammon and P. J. Rossky, J. Chem. Phys., 1984, 80, 4448.

46 T. A. Ho and A. Striolo, J. Chem. Phys., 2013, 138, 054117.

47 M. K. Rana and A. Chandra, J. Chem. Phys., 2013, 138, 204702. 